\section{EFFECTS OF EXTENDED-RELEASE METHYLPHENIDATE IN 109 CHILDREN WITH ATTENTION-DEFICIT/HYPERACTIVITY DISORDER: A CLINICAL ASSESSMENT}

Y. Ishida, T. Miyajima, S. Morichi, Y. Suganami, S. Oana, G. Yamanaka, A. Hoshika

Pediatrics, Tokyo Medical University, Tokyo, Japan

Background and aims: The basic treatments for patients with attention-deficit/hyperactivity disorder (ADHD) include psychosocial and medical therapymethylphenidate (MPH) is often used. The efficacy of immediate-release MPH (IR-MPH; Ritalin $®$ ) was proved; however, this drug was banned in Japan since December 2007, because its abuse among adults became a social issue. During this time, osmotic controlled-release oral system MPH (OROS-MPH; Concerta $囚$ ) was put on the market. We aimed to assess changes in ADHD clinical manifestations and frequency of OROS-MPHinduced side effects.

Methods: OROS-MPH was administered to 109 ADHD children (boys, 96; girls, 13; age, 7-16 years). To elucidate effects of this drug, we calculated changes in scores on ADHD Diagnostic and Statistical Manual of Mental disorders (DSM-IV) rating scale for children who continued intake of OROS-MPH for over 4 months and calculated the frequency ofsideeffects-electrocardiogramchanges, abdominal discomfort, appetite suppression, and neurological symptoms. We compared the drug efficacy and frequency of its side effects between isolated group comprising ADHD children (30 subjects) and merged group comprising children with ADHD and autism obstacle (79 subjects), including pervasive developmental disorder (PDD) and Asperger syndrome. In addition, we examined heights and weights of the subjects and compared these parameters with the standard growth curve for Japanese children.

Results and conclusions: OROS-MPH improved ADHD symptoms in children (not concerned with yes or no of autism obstacle merger) without having any severe side effects. However, the growth of OROS-MPH-treated children should be monitored.

\section{DELIBERATE SELF-HARM AND DRUG OVERDOSE}

\author{
A. Kumar, S. Sethuraman, D.N. Sobithadevi
}

Paediatrics, Queens Hospital Burton, Burton, UK

Background: $\mathrm{DSH}$ is the second most leading cause of death in young people in developed countries outside the USA. NICE have provided guidelines on the management and prevention of DSH.

Aim: To re-audit the care of children with DSH in an in-patient setting with view of adherence to the NICE guidelines.

Methodology: We analysed 32 children admitted with DSH to a paediatric ward in a 2-year period extending from January 2007 - December 2009. 32 case notes were analysed and compared to the NICE guidelines and the original 2007 audit.

Results: The age range was between 10-16 years (median 14) with $78 \%$ being females. $37.5 \%$ presented with paracetamol overdose, $43.7 \%$ mixed overdose and $18.7 \%$ physical harm. In the original audit $100 \%$ referrals were made to CAMHs compared to $93.7 \%$ (30/32) in 2010 of which $93.3 \%$ were made within 2 days of admission. 29 patients were assessed prior to discharge and were followed up in OP by CAMHs. Only $6 \%(11 \%$ in 2007$)$ had clear consent for referral to CAMHs documented in the notes.

Conclusion: Mixed overdose is the most common mode of DSH, with females the most prevalent demography. NICE guidelines recommend that all children with DSH should be admitted to an acute paediatric ward and be assessed by CAMHs prior to discharge. This audit illustrates that standards are not being met satisfactorily (93.7\%). Furthermore as per the guidelines better documentation is required. The availability of an out-of-hours CAMHs team would benefit the management of DSH in children. 